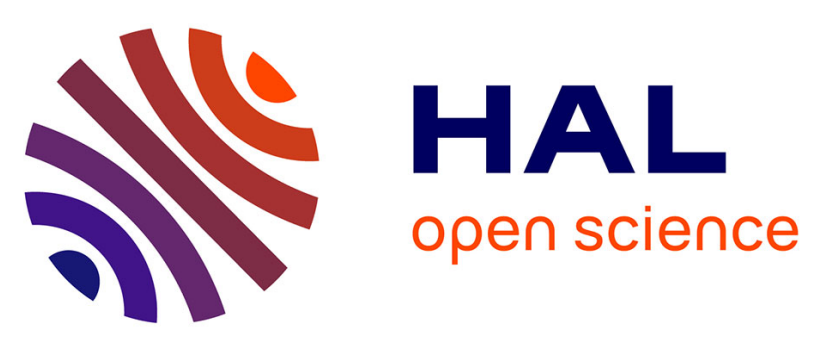

\title{
Characterization of Gas-Phase Organics Using Proton Transfer Reaction Time-of-Flight Mass Spectrometry: Residential Coal Combustion
}

Felix Klein, Simone Pieber, Haiyan Ni, Giulia Stefenelli, Amelie Bertrand, Dogushan Kilic, Brice Temime-Roussel, Nicolas Marchand, Veronika

Pospisilova, Imad El Haddad, et al.

\section{To cite this version:}

Felix Klein, Simone Pieber, Haiyan Ni, Giulia Stefenelli, Amelie Bertrand, et al.. Characterization of Gas-Phase Organics Using Proton Transfer Reaction Time-of-Flight Mass Spectrometry: Residential Coal Combustion. Environmental Science and Technology, 2018, 52 (5), pp.2612-2617. 10.1021/acs.est.7b03960 . hal-01710456

\section{HAL Id: hal-01710456 \\ https://hal.science/hal-01710456}

Submitted on 2 May 2018

HAL is a multi-disciplinary open access archive for the deposit and dissemination of scientific research documents, whether they are published or not. The documents may come from teaching and research institutions in France or abroad, or from public or private research centers.
L'archive ouverte pluridisciplinaire HAL, est destinée au dépôt et à la diffusion de documents scientifiques de niveau recherche, publiés ou non, émanant des établissements d'enseignement et de recherche français ou étrangers, des laboratoires publics ou privés. 


\section{Characterization of Gas-Phase Organics Using Proton Transfer Reaction Time-of-Flight Mass Spectrometry: Residential Coal Combustion}

Felix Klein, ${ }^{\dagger}$ Simone M. Pieber, ${ }^{\dagger}$ Haiyan Ni, ${ }^{\ddagger}$ Giulia Stefenelli, ${ }^{\dagger}$ Amelie Bertrand, ${ }^{\text {II }}$ Dogushan Kilic, ${ }^{\dagger}$ Veronika Pospisilova, ${ }^{\dagger}$ Brice Temime-Roussel, ${ }^{\text {II }}$ Nicolas Marchand, ${ }^{\text {II }}$ Imad El Haddad, ${ }^{\dagger}$ Jay G. Slowik, ${ }^{\dagger}$ Urs Baltensperger, ${ }^{\dagger}$ Junji Cao, ${ }^{\ddagger}$ Ru-jin Huang, ${ }^{*},+, \dagger$ and André S. H. Prévôt*, ${ }^{*}$

${ }^{\dagger}$ Laboratory of Atmospheric Chemistry, Paul Scherrer Institute, Villigen, 5232, Switzerland

${ }^{\ddagger}$ Key Lab of Aerosol Chemistry \& Physics, State Key Laboratory of Loess and Quaternary Geology, Institute of Earth Environment, Chinese Academy of Sciences, Xi'an, 710061, China

II Aix Marseille Univ, CNRS, LCE, Marseille, 13331, France

Supporting Information

ABSTRACT: Residential coal combustion is a significant contributor to particulate urban air pollution in Chinese mega cities and some regions in Europe. While the particulate emission factors and the chemical characteristics of the organic and inorganic aerosol from coal combustion have been extensively studied, the chemical composition and nonmethane organic gas (NMOG) emission factors from residential coal combustion are mostly unknown. We conducted 23 individual burns in a traditional Chinese stove used for heating and cooking using five different coals with Chinese origins, characterizing the NMOG emissions using a proton transfer reaction time-of-flight mass spectrometer. The measured emission factors range from 1.5 to $14.1 \mathrm{~g} / \mathrm{kg}_{\text {coal }}$ for bituminous coals and are below $0.1 \mathrm{~g} /$

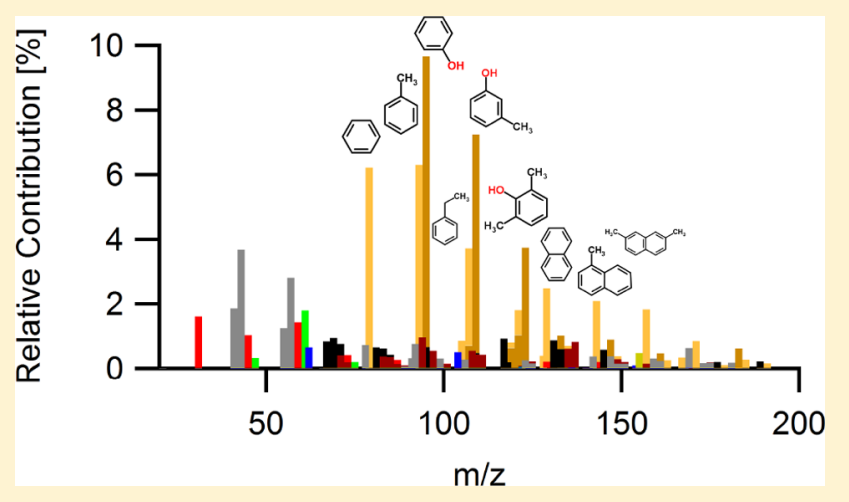
$\mathrm{kg}_{\text {coal }}$ for anthracite coals. The emission factors from the bituminous coals are mostly influenced by the time until the coal is fully ignited. The emissions from the bituminous coals are dominated by aromatic and oxygenated aromatic compounds with a significant contribution of hydrocarbons. The results of this study can help to improve urban air pollution modeling in China and Eastern Europe and can be used to constrain a coal burning factor in ambient gas phase positive matrix factorization studies.

\section{INTRODUCTION}

Coal combustion has been recently identified as an important source of primary organic aerosol in urban areas in China. ${ }^{1-5}$ Also in some regions in Europe, e.g. Poland, residential coal combustion is the dominant source of particulate air pollution outdoors as well as indoors. ${ }^{6}$ Recent studies also indicate that coal combustion could be an important source for both severe outdoor air pollution and indoor air pollution in India. ${ }^{7,8}$ While the emission factors and chemical composition of the organic carbon (OC) and elemental carbon (EC) or black carbon (BC) emitted by residential coal combustion have already been studied to a certain extent, ${ }^{9-14}$ there are, to our knowledge, only three studies so far investigating the gaseous emissions from residential coal combustion. ${ }^{15-17}$ Most of the compounds reported in these studies are toxic in higher concentrations and can act as precursors for ozone production or secondary organic aerosol (SOA) formation.

For creating emission inventories used for air pollution modeling and assessing impacts on indoor and outdoor air quality a complete picture of the emission factors and chemical composition of the nonmethane organic gases (NMOG) is needed. However, all three studies so far available measured the gaseous compounds offline with gas or liquid chromatography methods focusing on alkanes, alkenes, aromatics, and carbonyls, neglecting nontraditional volatile organic compounds like oxygenated aromatics which are highly toxic ${ }^{18}$ and have been recently identified as important precursors for SOA formation from residential wood combustion. ${ }^{19}$ The studies also indicate that the emissions from residential coal combustion vary significantly depending on the stove used as well as the type (sub-bituminous, bituminous, or anthracite), form (coal dust, briquettes, or honeycomb briquettes) and origin of coal burned. This indicates that more studies with different coal and burner

Received: August 2, 2017

Revised: January 12, 2018

Accepted: January 24, 2018

Published: February 13, 2018 
combinations are needed to better capture the diversity of combinations used in real world applications.

In our study we report the emission factors and chemical composition of the NMOG emissions from five different Chinese coals burned in a traditional Chinese stove used for heating or cooking as measured online with a proton transfer reaction timeof-flight mass spectrometer (PTR-ToF-MS). This data can be used to improve emission inventories in order to better constrain the influence of NMOG emitted by residential coal combustion on indoor and outdoor air quality in China, India, and parts of Europe.

\section{METHODS}

Experimental Setup and Procedure. Five different Chinese coals (Table 1) were burnt in a widely used Chinese

Table 1. Type, Origin, Volatile Matter Content $\left(V_{\text {daf }}\right)$, and Carbon Content (CC) of the Coals Used for This Study

\begin{tabular}{cllcc} 
coal & \multicolumn{1}{c}{ type } & \multicolumn{1}{c}{ origin } & $V_{\text {daf }}[\%]$ & CC $[\%]$ \\
A1 & anthracite & Shanxi & 6.85 & 78.2 \\
A2 & anthracite & Shaanxi & 8.28 & 77.3 \\
B1 & bituminous & Ningxia & 29.70 & 70.8 \\
B2 & bituminous & Inner Mongolia & 33.11 & 62.8 \\
B3 & bituminous & Yunnan & 28.49 & 71.9 \\
\hline
\end{tabular}

coal burner to investigate the emission rates and the chemical composition of the NMOG produced by residential coal combustion. The results of this study are derived from 23 individual burning experiments (Table S1). Three coals were of the bituminous type (from Ningxia (B1), Inner Mongolia (B2), and Yunnan (B3)) and two of the anthracite type (from Shanxi (A1) and Shaanxi (A2)). The coals used in this study are classified into anthracite and bituminous coal based on their volatile matter content $\left(V_{\mathrm{daf}}\right)$. According to the national standards of the People's Republic of China (GB/T 57512009), $V_{\text {daf }}$ for anthracite coal is less than or equal to $10 \%$, whereas bituminous coal has much higher $V_{\text {daf }}(>10 \%)$. Volatile matter contents of coals used in this study were measured by Shaanxi Coal Geological Laboratory Co., Ltd., China, on the basis of the national standards of the People's Republic of China (GB/T 212-2008). The small burner in which the coal was burned was situated in a containment connected to a chimney. The dimensions of the typical Chinese coal burner are $51 \mathrm{~cm} \times$ $31 \mathrm{~cm}$ (height $x$ diameter). The emissions were extracted from the chimney with a flow rate of about $1.5 \mathrm{l} / \mathrm{min}$ and led through a heated $\left(180^{\circ} \mathrm{C}\right)$ silco steel line to a dilution system consisting of two subsequent ejector diluters (Dekati Ltd., Kangasala, Finland). The first diluter was heated to $180^{\circ} \mathrm{C}$, the second diluter was unheated, both diluting the emission by a factor of 10 with zero air (737-250 series, AADCO Instruments, Inc., USA) resulting in a total dilution factor of about 100. After the dilution the emissions were transported to the gas-phase instruments through a short unheated Teflon line. A similar setup was used for a previous study ${ }^{20}$ and showed no significant losses for C10 and $\mathrm{C} 15$ compounds. The temperature in the combustion chamber was monitored with a thermocouple probe situated closely above the coal. A schematic of the setup and the burning procedure can be found in the Supporting Information (Figure S1).

To ignite the coal, first a honeycomb briquette of the A1 coal was ignited with wooden biomass in a separate burner, and this was then used to ignite about $200 \mathrm{~g}$ of the $\mathrm{Al}$ coal in the sampling burner. After about $1 \mathrm{~h}$ when the coal was fully ignited and the temperature above the coal reached $650 \mathrm{C}^{\circ}$ the background of the A 1 coal was measured for at least $5 \mathrm{~min}$. Then about $200 \mathrm{~g}$ of the sample coal (in pieces with approximately the same size) were put into the burner. The emissions were sampled for at least half an hour; by then typically the NMOG emissions dropped to almost zero due to the coal being completely ignited. For every coal we sampled twice the whole time until the coal was completely burned down in order to be sure that there were no significant NMOG emissions after the coal was burning (Figure S2). The carbon content of the different coals was determined by combustion of 100-300 mg of coal sanded down from bigger chunks, in an elemental analyzer (Flash HT, Thermo-Fisher).

Instrumentation. For the characterization of the NMOG emissions and estimation of the emission factors we used a proton transfer reaction time-of-flight mass spectrometer (PTRTOF-8000, Ionicon Analytik Ges.m.b.H., Innsbruck, Austria) measuring in the $\mathrm{H}_{3} \mathrm{O}^{+}$mode. In this way the PTR-ToF-MS measures NMOG with a proton affinity higher than that of water, including carbonyls, acids, and aromatic hydrocarbons, as well as alkanes with more than eight carbons and alkenes with more than two carbons. Detailed information about the instrument can be found in the works of Graus et al. ${ }^{21}$ and Jordan et al. ${ }^{22}$ The time resolution of the measurements was set to $10 \mathrm{~s}$ and the MCP voltage was set to $2300 \mathrm{~V}$. The instrument was operated with a drift voltage of $545 \mathrm{~V}$, a chamber temperature of $60^{\circ} \mathrm{C}$, and a drift pressure of 2.2 mbar resulting in an energy density $(E / N)$ of about $120 \mathrm{td}$ in the drift tube. The extraction voltage ( $\mathrm{Udx}$ ) was set to $35 \mathrm{~V}$. The mass accuracy and the relative transmission efficiency were routinely monitored by measuring calibration gas from a gas bottle containing aldehydes, ketones, aromatic compounds and trichlorobenzene (each $100 \mathrm{ppb}$ in nitrogen) with an $\mathrm{m} / z$ range from 31 to 181 .

The data was analyzed using the Tofware postprocessing software (version 2.4.2, TOFWERK AG, Thun, Switzerland; PTR module as distributed by Ionicon Analytik $\mathrm{GmbH}$, Innsbruck, Austria), running in the Igor Pro 6.3 environment (Wavemetrics Inc., Lake Oswego, OR, USA). The measured counts per seconds were converted to concentrations as described in the work of Klein et al. $^{23}$ without applying a fragmentation correction. As reaction rates against $\mathrm{H}_{3} \mathrm{O}^{+}$we used if known the literature values for our $E / N^{24}$ and otherwise a reaction rate of $k=2 \times 10^{-9} \mathrm{~cm}^{3} / \mathrm{s}$. The concentrations calculated are known to have an error of $10-15 \%$ if measuring high enough concentrations and provided good calibration of the instrument. ${ }^{25}$ A list with all the fitted ions, applied $k$-rates and family assignment of the ions can be found in the Supporting Information (Table S2). The concentration of water clusters in the drift tube was always less than $5 \%$ of the concentration of $\mathrm{H}_{3} \mathrm{O}^{+}$ions and therefore not considered for the calculations.

$\mathrm{CO}_{2}$ was measured using a $\mathrm{CO}_{2} / \mathrm{H}_{2} \mathrm{O}$ analyzer (Li-7000, LICOR Environmental, Lincoln, USA) and methane as well as nonmethane hydrocarbons (NMHC) were measured using a flame ionization hydrocarbon detector (FID, APHA-370, Horiba Ltd., Kyoto, Japan).

Emission Factor Calculation. To be able to compare the emissions from coal combustion to other emission sources we calculated the NMOG emission factors per kilogram coal burned. First the calculated concentrations were corrected for the exact dilution calculated from the difference of inflow to outflow of the ejector dilutors double checked with the dilution ratio of methane before and after dilution. The emissions were integrated over the first half hour after the start of the experiment and 


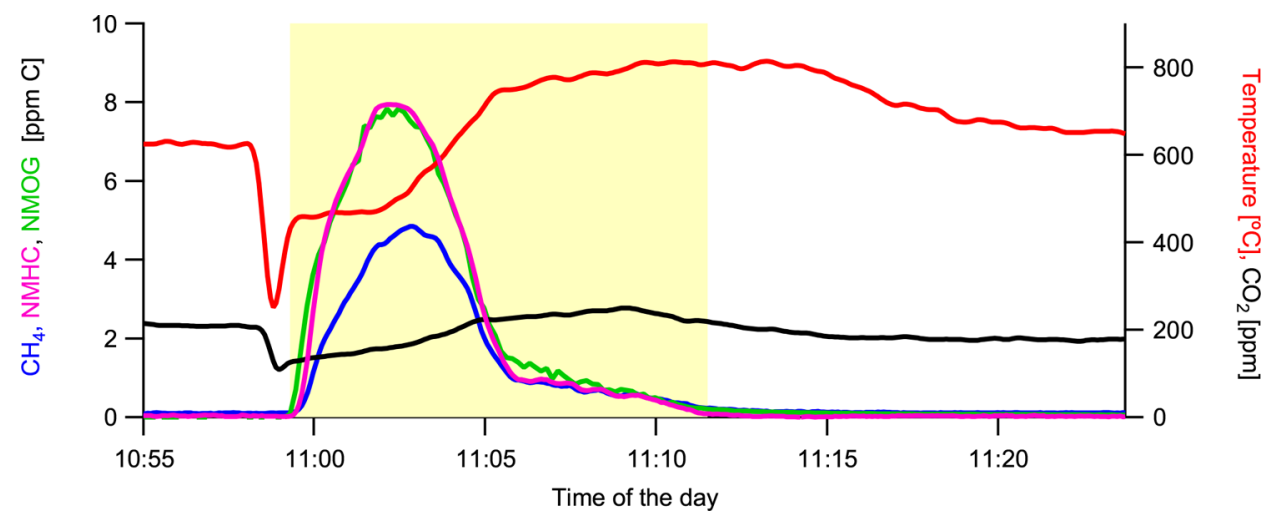

Figure 1. Time series of a typical coal burning experiment (B1) for methane $\left(\mathrm{CH}_{4}\right)$, total nonmethane hydrocarbons (NMHC) measured with the FID, total nonmethane organic gases (NMOG) measured with the PTR-ToF-MS, carbon dioxide $\left(\mathrm{CO}_{2}\right)$, and the temperature in the combustion chamber. The concentrations of methane, NMHC, and NMOG are background corrected. All concentrations are after 100 times dilution. The yellow shaded area begins when the sample coal is introduced and ends when complete ignition is achieved and the flaming phase begins.

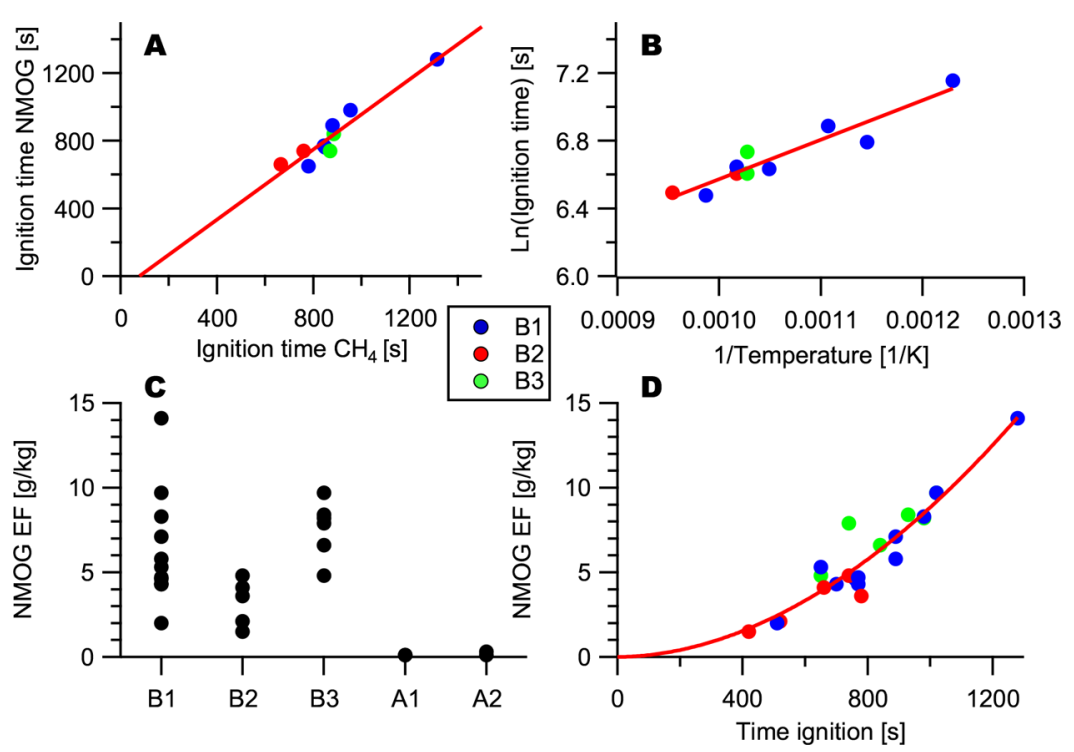

Figure 2. Correlation of the time until the coal is ignited (ignition time) with the average chamber temperature during the starting phase (B) and the influence of the ignition time on emission factors (C, D). Panel A compares the ignition times calculated from the evolution of either $\mathrm{NMOG}$ or $\mathrm{CH}_{4}$.

corrected for the background measured before addition of the sample. The emission factors were calculated according to eq 1 :

$$
\operatorname{NMOG} \text { EF }\left[\frac{\mathrm{g}}{\mathrm{kg}_{\text {coal }}}\right]=\frac{C_{i}\left[\frac{\mu \mathrm{g}}{\mathrm{m}^{3}}\right]}{C_{\mathrm{c}}\left[\frac{\mu \mathrm{g}}{\mathrm{m}^{3}}\right]} \times \mathrm{CC}\left[\frac{\mathrm{g}}{\mathrm{kg}_{\text {coal }}}\right]
$$

where $C_{i}$ is the concentration of a given compound, $C_{c}$ is the integrated carbon emissions from the coal retrieved from the integrated $\mathrm{CO}_{2}$ emissions measured during the full cycle experiments, and $\mathrm{CC}$ is the carbon content of the coal given in Table 1. The carbon emissions of $\mathrm{CO}, \mathrm{CH}_{4}$, and the NMOG were always below $5 \%$ of the carbon emissions due to $\mathrm{CO}_{2}$ and therefore neglected. The $\mathrm{CO}_{2}$ emissions had to be corrected for the background from the $\mathrm{Al}$ coal used to ignite the sample coal. We estimated the $\mathrm{CO}_{2}$ background from the amount of Al coal used for ignition and the time the Al coal was lit before adding the sample coal.

\section{RESULTS AND DISCUSSION}

Coal Burning Emission Factors. More than 95\% of the NMOG emissions of residential coal combustion are released within the first $15-20 \mathrm{~min}$ after the coal is put into the stove. We define the time until full ignition as the time from the start of the experiment until the total NMOG emissions drop below 5\% of their peak value (yellow shaded area in Figure 1). To validate this method we compared the ignition times calculated from the evolution of either methane or total NMOG using the 5\% threshold (Figure 2A). The estimated times until full ignition of NMOGs and methane are well-correlated $\left(R^{2}=0.91\right.$, slope $=$ 1.04). The ignition times also correlate well with times calculated by using ten times the standard deviation as threshold concentration (Figure S3). During the flaming phase the NMOG emissions are close to the detection limit of our instruments (Figure 1). The carbon mixing ratios calculated from the PTR-ToF-MS mass spectra compare well with the mixing ratios measured by the FID, showing that there are no significant emissions of smaller alkanes and alkenes which are not measured by PTR-ToF-MS. In general the FID does not efficiently measure oxygenated compounds, but the oxygenated aromatics we detect with the PTR-ToF-MS should have response factors above $0.8 .^{26}$

The length of the starting phase (time until full ignition) shows an exponential behavior, decreasing with increasing average temperature in the combustion chamber during the starting 


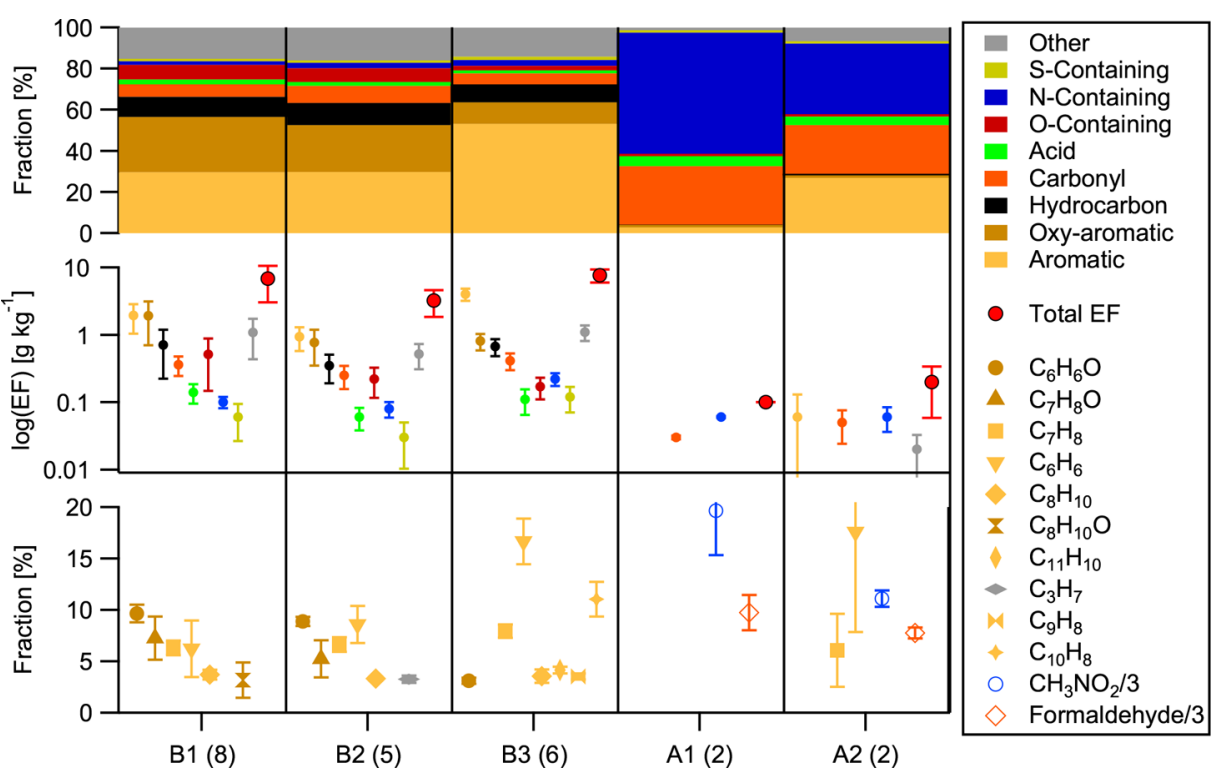

Figure 3. Relative contributions of different families to total NMOG mass (upper panel), the emission factors of these families (middle panel), and the compounds contributing more than $3 \%$ to the total mass (lower panel) from burning five different coals as measured with the PTR-ToF-MS. The number in brackets are the number of repeats. The error bars depict the standard deviation for B1, B2, and B3 and the range of results for A1 and A2.

phase (Figure 2B). The time until full ignition is influenced by the amount of coal used, the size of the pieces, and the temperature of the coal used to ignite the sample. Even though we tried to keep these parameters constant, the longest starting phase is three times longer than the shortest one. The results indicate that the nature (structure) of the coal could also play a significant role with $\mathrm{B} 2$ having shorter ignition times than B3 (Figure 2D).

The total NMOG emission factors of the bituminous coals in $\mathrm{g}$ per $\mathrm{kg}$ coal varied by more than a factor of 5 between the coals as well as for the same coals (Figure 2C). The emission factors for the B1, B2, and B3 coal range from about 2.0 to $14.1,1.5$ to 4.8 , and 4.8 to $9.7 \mathrm{~g} / \mathrm{kg}$, respectively. The total NMOG emission factors of the anthracite coals are $0.1 \mathrm{~g} / \mathrm{kg}$ close to the detection limit of the instruments. The spread in emission factors within the coals but also between the bituminous coals can be explained by the different times until ignition. The emission factors increase exponentially with an increasing time until full ignition for all the three tested bituminous coals. It seems that the B3 coal takes generally longer to ignite than the $\mathrm{B} 2$ coal, probably due to different degrees of layering as shown in the next section. Our results indicate that enhancing starting conditions (higher temperatures, smaller pieces) in the stoves or using anthracite instead of bituminous coals could help reducing NMOG emissions from residential coal combustion significantly.

Our emission factors compare well with previously reported volatile organic compound emission factors from bituminous coal smoldering combustion of $5.4 \pm 2.0 \mathrm{~g} / \mathrm{kg}$ reported by Liu et al. ${ }^{15}$ even though the chemical composition reported by Liu et al. is quite different from the one in this study as shown in the next section. Tsai et al. ${ }^{16}$ report much lower NMHC emission factors than observed in this study for the combustion of honeycomb briquettes. These are easier to ignite so most likely the time until full ignition is shorter, and they partly consist of clay which reduces the emission factor per kilogram. On the other hand, the emission factors of 5 and $6.5 \mathrm{~g} / \mathrm{kg}$ total NMHC for washed and unprocessed coal powder, ${ }^{16}$ respectively, compare well with the results of this study. The NMOG emission factors from residential coal combustion are comparable to the NMOG emission factors from residential wood combustion of $6.0 \pm 5.0$ $\mathrm{g} / \mathrm{kg}$ for beech, ${ }^{27} 6.7 \mathrm{~g} / \mathrm{kg}$ for oak, ${ }^{28}$ and $6.2-55.3 \mathrm{~g} / \mathrm{kg}$ for a hardwood mixture. ${ }^{29}$ In recent years, residential wood combustion has received considerable attention as a significant NMOG source, and these results indicate that residential coal combustion should likewise be considered. All the emission factors of this study in grams per kilogram of coal can be found in the Supporting Information (Table S3).

Chemical Composition. The emissions from the anthracite coal are close to the detection limit of the instrument, thus the chemical composition is quite uncertain (Figure 3). The emissions from the bituminous type coals are dominated by aromatic compounds. The composition of the B1 and B2 coal are comparable with about $25 \%$ aromatic and oxygenated aromatic compounds as well as $10 \%$ hydrocarbon-like compounds and $20 \%$ other compounds (unknown chemical structure and fragments), most likely derived from higher molecular weight alkanes. B3 emits about 50\% aromatic compounds but much less oxygenated aromatic compounds (10\%) than B1 and B2. The reason for these differences is most likely a different nature of the coals due to different temperatures and pressures during the formation of the coals. ${ }^{30}$ The emissions of the bituminous coals are dominated $(35-50 \%)$ by nine oxygenated and nonoxygenated compounds as well as $\mathrm{C}_{3} \mathrm{H}_{7}^{+}$which is due to propene and/or fragments from larger alkanes. These findings are in large contrast to the chemical composition of emissions from coal combustion recently reported by Liu et al. ${ }^{15}$ Liu et al. reported that alkane, alkene, and carbonyls comprised up to $70 \%$ of emissions from smoldering coal combustion, with $30 \%$ contribution from aromatic compounds. One reason for this difference can be that Liu et al. missed the oxygenated aromatics due to the use of GC-MS measurements. A second reason is that they reported quite high amounts of small alkanes and alkenes, measured by GC-MS, which we are not able to detect with the PTR-ToF-MS. However, due to the good agreement between the carbon mixing ratios derived from our PTR-ToF-MS measurements and the NMHC carbon mixing ratios retrieved from the THC monitor (Figure 1), we conclude that these compounds do not significantly contribute to the emissions of 
the coals measured during this study. This is supported by the finding of Nelson and Tyler $^{31}$ that volatilization of aliphatic compounds trapped in the coal structure has only a small yield from coal pyrolysis.

Emissions from $\mathrm{B} 1$ and $\mathrm{B} 2$ are dominated by phenol $\left(\mathrm{C}_{6} \mathrm{H}_{6} \mathrm{O}\right)$, cresols $\left(\mathrm{C}_{7} \mathrm{H}_{8} \mathrm{O}\right)$, toluene $\left(\mathrm{C}_{7} \mathrm{H}_{8}\right)$, benzene $\left(\mathrm{C}_{6} \mathrm{H}_{6}\right)$, xylenes/ ethylbenzene $\left(\mathrm{C}_{8} \mathrm{H}_{10}\right)$, and xylenols $\left(\mathrm{C}_{8} \mathrm{H}_{10} \mathrm{O}\right)$ as well as for $\mathrm{B} 2$ the ion $\mathrm{C}_{3} \mathrm{H}_{7}^{+}$. The emissions from $\mathrm{B} 3$ are clearly dominated by benzene with significant contributions from naphthalene $\left(\mathrm{C}_{8} \mathrm{H}_{10}\right)$ and toluene, and minor contributions from benzaldehyde, xylene/ethylbenzene, methylnaphthalene $\left(\mathrm{C}_{11} \mathrm{H}_{10}\right)$ and indene $\left(\mathrm{C}_{9} \mathrm{H}_{8}\right)$. These differences in emissions can be explained by different maturities of the coals (Table 1) leading to increased layering of the aromatic rings, as explained in the study of Achten and Hoffmann. ${ }^{30}$ The difference in the chemical composition between B1, B2, and B3 can also be seen from the $\mathrm{H}: \mathrm{C}$ and $\mathrm{O}: \mathrm{C}$ ratios of the primary NMOG emissions. The $\mathrm{H}: \mathrm{C}$ and $\mathrm{O}: \mathrm{C}$ ratios (as seen with the PTR-ToF-MS) of B1, B2, and B3 are 1.17 and $0.07,1.18$ and 0.08 , and 1.03 and 0.04 , respectively. The $\mathrm{H}: \mathrm{C}$ ratios of the emissions are slightly higher than the ones reported by Van Loo and Koppejan ${ }^{32}$ for raw coal itself $(0.4-1)$, but the O:C ratios lie well within the range of the bituminous coals $(0.01-0.2)$ with $\mathrm{B} 1$ and $\mathrm{B} 2$ being more in the sub-bituminous range and $\mathrm{B} 3$ being at the lower end, closer to the ratios of the anthracite coals. This suggests that the emitted compounds already exist in the coals rather than being formed during the combustion. Nelson and Tyler ${ }^{31}$ propose that at temperatures above $600{ }^{\circ} \mathrm{C}$ long-chain polymethylene groups in the coal decompose and release the aromatics which are bound to them. Reference spectra of the five coals can be found in the Supporting Information (Figure S4).

Another influence on the chemical composition of the emissions arises from the temperatures during the starting phase (Figure 4), which contributes to the variations in relative composition observed across all experiments (Figure 3). More specifically, the relative contribution of oxygenated aromatics decreases with increasing temperature, while the reverse is true for the nonoxygenated aromatics (Figure 4A). The relative contributions of hydrocarbons, other compounds (strongly

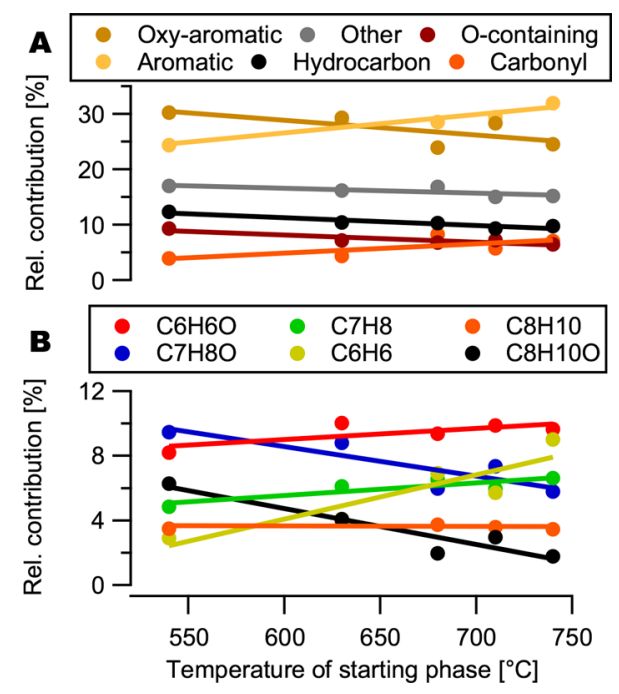

Figure 4. Change in the relative contribution of the main families (A) and compounds (B) to the total NMOG emissions of coal B1 with a changing starting phase temperature in the combustion chamber closely above the coal. influenced by hydrocarbon fragments) and oxygen containing compounds decreases while the relative contribution of carbonyls also increases with temperature. The decrease of the oxygenated aromatics is mostly manifested in a declining relative contribution of the cresols and xylenols while the increase in nonoxygenated aromatics mostly relates to an increase in benzene and toluene. Phenol also increases slightly while the relative contribution of the xylenes is constant. This fits well with findings about the changing yields of aromatic compounds during pyrolysis of coal with changing temperature reported by Nelson and Tyler. ${ }^{31}$ In that study the authors reported a steep increase of benzene and toluene yields with increasing temperature while the yield of the cresols stayed constant or even declined (due to decomposition) within our temperature range (since our temperatures were measured above the coal we expect them to be lower than the ones reported by Nelson and Tylor $^{31}$ for the pyrolysis). Also the finding that the emissions of alkanes declines with temperature is supported by Nelson and Tylor reporting a strong decline of alkane yields with temperatures increasing above $500{ }^{\circ} \mathrm{C}$. This shows the need for the estimation of the SOA potential from coal combustion precursors generated from combustion at different temperatures to understand if this change in composition influences the SOA production and thus could be used to reduce particulate air pollution through secondary aerosol formation from coal combustion.

\section{ASSOCIATED CONTENT}

\section{Supporting Information}

The Supporting Information is available free of charge on the ACS Publications website at DOI: 10.1021/acs.est.7b03960.

List of all coal burning experiments including the experiment conditions, the list of all emission factors, the list with the exact $m / z, k$ values, and family attributions for all ions, raw PTR-ToF-MS spectra for all five coals, and a schematic of the experimental setup (PDF)

\section{AUTHOR INFORMATION}

\section{Corresponding Authors}

*E-mail: rujin.huang@ieecas.cn (R.-j.H.).

*E-mail: andre.prevot@psi.ch (A.S.H.P.).

ORCID

Felix Klein: 0000-0002-3680-4735

Dogushan Kilic: 0000-0003-4001-0177

Notes

The authors declare no competing financial interest.

\section{ACKNOWLEDGMENTS}

F.K. received financial support from the SNF (Swiss National Science Foundation) within the project AEROCOOK. S.M.P. acknowledges support from the SNF (WOOSHI, 140590). G.S., V.P., and J.G.S. are supported by an SNF starting grant (BSSGI0_155846). This study was financially supported by the National Natural Science Foundation of China (NSFC) under Grant Nos. 91644219 and 21661132005 . Special thanks to René Richter for his valuable technical assistance during the campaign.

\section{REFERENCES}

(1) Elser, M.; et al. New insights into $\mathrm{PM}_{2.5}$ chemical composition and sources in two major cities in China during extreme haze events using aerosol mass spectrometry. Atmos. Chem. Phys. 2016, 16, 3207-3225. 
(2) Ge, X.; Li, L.; Chen, Y.; Chen, H.; Wu, D.; Wang, J.; Xie, X.; Ge, S.; $\mathrm{Ye}, \mathrm{Z}$; $\mathrm{Xu}, \mathrm{J}$.; Chen, M. Aerosol characteristics and sources in Yangzhou, China resolved by offline aerosol mass spectrometry and other techniques. Environ. Pollut. 2017, 225, 74-85.

(3) Huang, R.-J.; et al. High secondary aerosol contribution to particulate pollution during haze events in China. Nature 2014, 514, 218-222.

(4) Li, H.; Zhang, Q.; Zhang, Q.; Chen, C.; Wang, L.; Wei, Z.; Zhou, S.; Parworth, C.; Zheng, B.; Canonaco, F.; Prévôt, A. S. H.; Chen, P.; Zhang, H.; He, K. Wintertime aerosol chemistry and haze evolution in an extremely polluted city of North China Plain: significant contribution from coal and biomass combustions. Atmos. Chem. Phys. Discuss. 2017, 2017, $1-31$

(5) Zhou, S.; Yang, L.; Gao, R.; Wang, X.; Gao, X.; Nie, W.; Xu, P.; Zhang, Q.; Wang, W. A comparison study of carbonaceous aerosols in a typical North China Plain urban atmosphere: Seasonal variability, sources and implications to haze formation. Atmos. Environ. 2017, 149, 95-103.

(6) Junninen, H.; et al. Quantifying the impact of residential heating on the urban air quality in a typical European coal combustion region. Environ. Sci. Technol. 2009, 43, 7964-7970.

(7) Kalaiarasan, G.; Balakrishnan, R. M.; Khaparde, V. Receptor model based source apportionment of in the metropolitan and industrialized areas of Mangalore. Environ. Technol. Innovation 2016, 6, 195-203.

(8) Suryawanshi, S.; Chauhan, A. S.; Verma, R.; Gupta, T. Identification and quantification of indoor air pollutant sources within a residential academic campus. Sci. Total Environ. 2016, 569-570, 4652.

(9) Shen, G.; et al. Pollutant emissions from improved coal- and woodfuelled cookstoves in rural households. Environ. Sci. Technol. 2015, 49, 6590-6598.

(10) Shen, G.; Yang, Y.; Wang, W.; Tao, S.; Zhu, C.; Min, Y.; Xue, M.; Ding, J.; Wang, B.; Wang, R.; Shen, H.; Li, W.; Wang, X.; Russell, A. G. Emission factors of particulate matter and elemental carbon for crop residues and coals burned in typical household stoves in China. Environ. Sci. Technol. 2010, 44, 7157-7162.

(11) Chen, Y.; Tian, C.; Feng, Y.; Zhi, G.; Li, J.; Zhang, G. Measurements of emission factors of PM2.5, OC, EC, and BC for household stoves of coal combustion in China. Atmos. Environ. 2015, 109, 190-196.

(12) Zhi, G.; Chen, Y.; Feng, Y.; Xiong, S.; Li, J.; Zhang, G.; Sheng, G.; $\mathrm{Fu}, \mathrm{J}$. Emission characteristics of carbonaceous particles from various residential coal-stoves in China. Environ. Sci. Technol. 2008, 42, 33103315.

(13) Zhang, Y.; Schauer, J. J.; Zhang, Y.; Zeng, L.; Wei, Y.; Liu, Y.; Shao, M. Characteristics of particulate carbon emissions from real-world Chinese coal combustion. Environ. Sci. Technol. 2008, 42, 5068-5073.

(14) Chen, Y.; Zhi, G.; Feng, Y.; Fu, J.; Feng, J.; Sheng, G.; Simoneit, B. R. T. Measurements of emission factors for primary carbonaceous particles from residential raw-coal combustion in China. Geophys. Res. Lett. 2006, 33, L20815.

(15) Liu, C.; Zhang, C.; Mu, Y.; Liu, J.; Zhang, Y. Emission of volatile organic compounds from domestic coal stove with the actual alternation of flaming and smoldering combustion processes. Environ. Pollut. 2017, $221,385-391$.

(16) Tsai, S. M.; Zhang, J.; Smith, K. R.; Ma, Y.; Rasmussen, R.; Khalil, M. Characterization of non-methane hydrocarbons emitted from various cookstoves used in China. Environ. Sci. Technol. 2003, 37, 2869-2877.

(17) Wang, Q.; Geng, C.; Lu, S.; Chen, W.; Shao, M. Emission factors of gaseous carbonaceous species from residential combustion of coal and crop residue briquettes. Front. Environ. Sci. Eng. 2013, 7, 66-76.

(18) Lundstedt, S.; White, P. A.; Lemieux, C. L.; Lynes, K. D.; Lambert, I. B.; Öberg, L.; Haglund, P.; Tysklind, M. Sources, fate, and toxic hazards of oxygenated polycyclic aromatic hydrocarbons (PAHs) at PAH- contaminated sites. Ambio 2007, 36, 475-485.

(19) Bruns, E. A.; El Haddad, I.; Slowik, J. G.; Kilic, D.; Klein, F.; Baltensperger, U.; Prévôt, A. S. H. Identification of significant precursor gases of secondary organic aerosols from residential wood combustion. Sci. Rep. 2016, 6, 27881.

(20) Klein, F.; Farren, N. J.; Bozzetti, C.; Daellenbach, K. R.; Kilic, D.; Kumar, N. K.; Pieber, S. M.; Slowik, J. G.; Tuthill, R. N.; Hamilton, J. F.; Baltensperger, U.; Prévôt, A. S. H.; El Haddad, I. Indoor terpene emissions from cooking with herbs and pepper and their secondary organic aerosol production potential. Sci. Rep. 2016, 6, 36623.

(21) Graus, M.; Muller, M.; Hansel, A. High resolution PTR-TOF: Quantification and formula confirmation of VOC in real time. J. Am. Soc. Mass Spectrom. 2010, 21, 1037-1044.

(22) Jordan, A.; Haidacher, S.; Hanel, G.; Hartungen, E.; Mark, L.; Seehauser, H.; Schottkowsky, R.; Sulzer, P.; Mark, T. D. A high resolution and high sensitivity proton-transfer-reaction time-of-flight mass spectrometer (PTR-TOF-MS). Int. J. Mass Spectrom. 2009, 286, $122-128$.

(23) Klein, F.; et al. Characterization of gas-phase organics using proton transfer reaction time-of-flight mass spectrometry: cooking emissions. Environ. Sci. Technol. 2016, 50, 1243-1250.

(24) Cappellin, L.; Probst, M.; Limtrakul, J.; Biasioli, F.; Schuhfried, E.; Soukoulis, C.; Märk, T. D.; Gasperi, F. Proton transfer reaction rate coefficients between $\mathrm{H}_{3} \mathrm{O}^{+}$and some sulphur compounds. Int. J. Mass Spectrom. 2010, 295, 43-48.

(25) de Gouw, J. A.; Goldan, P. D.; Warneke, C.; Kuster, W. C.; Roberts, J. M.; Marchewka, M.; Bertman, S. B.; Pszenny, A. A. P.; Keene, W. C. Validation of proton transfer reaction-mass spectrometry (PTRMS) measurements of gas-phase organic compounds in the atmosphere during the New England Air Quality Study (NEAQS) in 2002. J. Geophys. Res.: Atmos. 2003, DOI: 10.1029/2003JD003863.

(26) Tong, H. Y.; Karasek, F. W. Flame ionization detector response factors for compound classes in quantitative analysis of complex organic mixtures. Anal. Chem. 1984, 56, 2124-2128.

(27) Bruns, E. A.; Slowik, J. G.; El Haddad, I.; Kilic, D.; Klein, F.; Dommen, J.; Temime-Roussel, B.; Marchand, N.; Baltensperger, U.; Prévôt, A. S. H. Characterization of gas-phase organics using proton transfer reaction time-of-flight mass spectrometry: fresh and aged residential wood combustion emissions. Atmos. Chem. Phys. 2017, 17, $705-720$.

(28) Schauer, J. J.; Kleeman, M. J.; Cass, G. R.; Simoneit, B. R. T. Measurement of emissions from air pollution sources. 3. C1-C29 Organic compounds from fireplace combustion of wood. Environ. Sci. Technol. 2001, 35, 1716-1728.

(29) McDonald, J. D.; Zielinska, B.; Fujita, E. M.; Sagebiel, J. C.; Chow, J. C.; Watson, J. G. Fine particle and gaseous emission rates from residential wood combustion. Environ. Sci. Technol. 2000, 34, 20802091.

(30) Achten, C.; Hofmann, T. Native polycyclic aromatic hydrocarbons (PAH) in coals - A hardly recognized source of environmental contamination. Sci. Total Environ. 2009, 407, 2461-2473.

(31) Nelson, P.; Tyler, R. Formation of light gases and aromatic species during the rapid pyrolysis of coal. Symp. (Int.) Combust., [Proc.] 1988, 21, 427-435.

(32) Van Loo, S., Koppejan, J. The Handbook of Biomass Combustion and Co-firing; Routledge, 2010. 